\title{
Como e Por Que Entrar em Árvores
}

\author{
SÉRGIO MEDEIROS \\ Universidade Federal de Santa Catarina
}

\begin{abstract}
Native American Literature shows women having sexual relations with trees. An animal (bird or monkey) can help the partners to interact with one another. This paper discusses three myths that speak of women who gave birth to children after being seduced by a vegetal being.
\end{abstract}

Keywords: Women; trees; animals; children; Native American literature

A antropologia contemporânea mostra que, para muitos povos, a maioria das plantas e dos animais são pessoas como nós, o que põe em xeque a distinção entre natureza e cultura sancionada pelo bom senso ou, se se quiser, pelo modo de pensar ocidental. Philippe Descola afirma que, para os achuar, que habitam na fronteira entre o Equador e o Peru, a humanidade das plantas e dos animais não é física (não repousa na aparência), mas moral ou espiritual. Assim, mesmo mantendo sua forma habitual, esses seres possuiriam uma "alma" análoga à dos humanos, o que lhes permitiria pensar, julgar, ter sentimentos, comunicar-se usando palavras compreensíveis, sobretudo durante os sonhos, quando despem sua aparência natural e apresentam-se ao sonhador como homens e mulheres comuns.

Discutirei a seguir uma terceira possibilidade: a "aparência amoral," ou até mesmo "imoral," de certas árvores e frutas, a fim de poder apresentar não o vasto "perspectivismo ameríndio," que Eduardo Viveiros de Castro define como o animismo "levado às últimas consequências, como só os índios sabem fazê-lo" (137), mas uma certa estratégia de sedução utilizada por um protagonista sobre-humano; a ação da divindade se define claramente como 
transgressora, e é compreendida assim pelos personagens humanos envolvidos. Em outras palavras, dentro do universo intermediário entre natureza e cultura, tratarei de um tema ameríndio muito difundido nas Américas: o da moça virgem que é violada por um ser sobre-humano que utiliza uma árvore frutífera, na qual ele momentaneamente encarna, para realizar seu intento. Neste caso, a árvore representa, por meio da metonímia (contém o sumo ou o sêmen do violador), a divindade, mas apenas temporariamente, não podendo, de modo algum, ser confundida com ela. A árvore não é necessariamente uma divindade nem um ser humano, mas apenas a morada temporária, nos mitos sobre sedução e violação de que falarei, do protagonista sobrenatural.

Oferecerei três exemplos literários conhecidos que, a meu ver, merecem ser comparados entre si, pois suas convergências e divergências são elucidativas e ajudarão a esclarecer a questão que proponho ao leitor: por que, nos mitos indígenas, ocorre o intercurso sexual com árvores? Em todos os exemplos, as mulheres são fecundadas, sem seu consentimento explícito, por protagonistas que não querem revelar sua verdadeira identidade e guardam seu sêmen em frutos atraentes e saboroso.

O manuscrito de Huarochiri é uma cosmogonia andina escrita por autóctones, no início do século XVII, que registra as crenças religiosas indígenas. Considerado um dos grandes textos literários nativos, foi redigido em quéchua, a língua indígena mais usada na época. Retiro do capítulo 2 dessa cosmogonia o primeiro exemplo do que me proponho a discutir a seguir. No trecho que destacarei, a árvore frutífera é parceira sexual de uma divindade que se recusa a ter relações com o outro sexo. Utilizarei a edição preparada por Frank Salomon e George L. Urioste, que traz a tradução do texto para o inglês acompanhada do original em quéchua, mas consultarei também a tradução para o francês, igualmente bilíngue, de Gerald Taylor. No referido capítulo (em tradução inédita de minha autoria), lê-se a respeito da divindade que protagoniza a cena de sedução:

Há muito tempo, Cuni Raya Vira Cocha costumava passear sob a aparência de um homem miserável e sem amigos, com uma manta e uma túnica rasgadas e andrajosas. Algumas pessoas que não perceberam quem ele era, gritaram-lhe: "Velho piolhento e miserável!" 
Contudo, foi esse homem quem modelou todos os povoados. Somente com a sua fala ele fez os campos e concluiu os terraços com muros de ótima alvenaria. Quanto aos canais de irrigação, ele os abriu a partir de suas fontes apenas lançando a flor de um junco chamado pupuna.

Depois disso, ele continuou fazendo todos os tipos de prodígio, deixando alguns dos huacas locais humilhados com a sua inteligência.

Veremos a seguir como essa divindade andina (um huaca) entrou numa árvore, literalmente, ao introduzir seu sêmen dentro de uma fruta madura, com o propósito de engravidar, contra a vontade dela, uma virgem, ela também uma divindade, que desejava manter-se intocada por homens, fossem seres sobrehumanos ou não. Ou seja, a divindade feminina, ao abrigo da sombra de uma árvore, foi violentada (sua indignada reação posterior explicita o sentimento de ter sido violada) pela divindade masculina, que, primeiro, pairou disfarçada em pássaro sobre sua cabeça e, depois, "caiu” a seus pés, assumindo (uma parte do corpo dele, ao menos) a forma de uma fruta madura, que ela inadvertidamente devorou. Eis o que afirma o trecho em questão:

Havia nessa época uma huaca chamada Caui Llaca. Caui Llaca permaneceu virgem.

Como era muito bonita, todos os huacas e villcas a desejavam. "Tenho de dormir com ela!", eles pensavam.

Numa ocasião, esta mulher, que jamais havia permitido que qualquer homem a tocasse, estava tecendo sob a árvore lúcuma.

Cuni Raya, graças à sua inteligência, transformou-se num pássaro e voou até a lúcuma.

Ele colocou seu sêmen numa fruta que havia amadurecido e a derrubou perto da mulher. A mulher a sorveu prazerosamente.

Assim, ela ficou grávida, mesmo sem ter sido tocada por um homem.

Nove meses depois, embora fosse virgem, ela deu à luz uma criança, como sucede a todas as mulheres grávidas. 
E assim, também como as outras mulheres, durante um ano ela amamentou a criança, perguntando-se: "De quem poderá ser esta criança?"

Nesse trecho, a virgem é finalmente enganada por um de seus pretendentes, mas ambos os personagens não são pessoas quaisquer, porém huacas, ou seja, divindades ancestrais. O termo huaca é amplo e pode se referir, como explicam Salomon e Urioste, a todos os objetos físicos que personificam pessoas sobrehumanas e sagradas. Por isso, entre os antigos povos andinos, muitas montanhas, fontes, confluências de rios, múmias e objetos manufaturados também eram considerados huacas. O termo villca, que aparece também no trecho citado, refere-se a um ser humano que compartilha a condição de huaca.

Cuni Raya é uma divindade aquática associada à irrigação; os incas pensavam que a habilidade de criar rios e nascentes era o único signo do seu poder, segundo Salomon e Arioste. Porém, em O manuscrito de Huarochiri, sua caracterização é muito mais complexa do que essa definição, pois ele aparece como Cuni Raya Vira Cocha, o que imediatamente sugere que sua natureza é comparável, nessa cosmogonia, à de Vira Cocha, divindade da região montanhosa que era apoiada pelos incas, o povo dominante. Cuni Raya e Vira Cocha são, portanto, divindades "quase semelhantes," como o texto deixa entender. Quero também destacar que Cuni Raya é, sobretudo, um trickster, uma divindade errante capaz de transformar-se, como se viu, num pássaro. ${ }^{1} \mathrm{Na}$ condição de pássaro, conseguiu inserir seu sêmen numa fruta da árvore lúcuma (árvore frutífera nativa do Peru), tornando-a especialmente sumarenta, com a qual violentará a virgem.

A virgem Caui Llaca provou, de fato, a seguir, dessa estranha fruta, sem suspeitar que, graças à sua gula, estava recebendo a "semente" da divindade aquosa, se posso expressar-me dessa maneira, levando em conta que o trickster, na cosmogonia, é responsável por transformações hidráulicas. A cosmogonia

\footnotetext{
1 Como todos os heróis míticos, também o trickster é um modelo de comportamento, embora sua atuação seja sempre intrigante e paradoxal. Hermes, Exu ou Coiote são exemplos estudados por Hyde. Que moral se poderia extrair das suas narrativas, que em geral são absurdas e cômicas? Seria melhor aprender a jogar com ele, afirma Hyde. Após a desordem provocada pelas ações irresponsáveis do trickster, o mundo sempre renasce, parecendo-se, porém, cada vez mais com o mundo no qual vivemos.
} 
afirma que Cuni Raya Vira Cocha, considerados em conjunto como duas divindades semelhantes, encherem o mundo com seres. Pode-se concluir que o filho de Caui Llana, inicialmente não desejado ou programado pela mãe, é um exemplo dessa capacidade de gerar seres, geralmente por meios não convencionais ou mágicos.

Especialista em disfarces, Cuni Raya surge inicialmente vestido de mendigo, negando seu caráter sobre-humano, o que só comprova sua ousadia de trickster. O trickster tem uma personalidade multiforme e sua aparência é variável e imprevisível, sendo capaz, como se viu, de transformar-se em um animal, conforme a conveniência. Na abertura da cosmogonia, ele surge sem amigos, usando uma túnica em farrapos; todos o supõem um pobre comum a quem não se deve dar atenção. Chegam a agredi-lo, chamando-o, por exemplo, de velho desprezível e miserável. Evidentemente, como divindade, era muito inteligente e podia fazer todos os tipos de prodígio. Mas preferia o anonimato, por assim dizer, assumindo a aparência mais humilde e abjeta possível, dentro do contexto da época primordial. É nessa condição "baixa", de pessoa desclassificada, que ousa violar a virgem.

Caui Llana, que era muito bonita e cobiçada, desprezou naturalmente o "velho piolhento" que muitos humilhavam. Mas ele acabou conseguindo, se não dormir com ela, como os demais homens desejavam, pelo menos engravidá-la, ao ofertar-lhe, sub-repticiamente, como fazem os trickesters, a fruta com o seu sêmen. Quando nasce a criança e a mulher descobre quem é o pai dela, fica indignada porque não pode admitir que tenha gerado um filho do velho mendigo que ela sempre desprezara. Ela então foge para o mar levando o filho; Cuny Raya Vira Cocha veste então sua roupa dourada ("Ela logo me desejará!", é seu único pensamento, ao paramentar-se assim) e corre atrás da enfurecida divindade, que ainda ignora a verdadeira identidade do pai da criança. O tema da beleza física realçada pela imponência do vestuário é crucial, neste trecho da cosmogonia, pois, ao tentar se aproximar da deusa fugitiva, o huaca lhe diz (tradução minha), fazendo o elogio da sua própria aparência:

"Irmã Caui Llaca!" ele a chamou. "Ei, olhe para mim. Agora estou realmente bonito!" ele disse, e permaneceu ali fazendo sua roupa cintilar. Caiu Llana nem mesmo virou-se para olhar. 
"Porque dei à luz uma criança desse rufião, desse mendigo sarnento, vou logo desaparecer no mar", ela disse. Ela se dirigiu imediatamente para o mar profundo perto de Pacha Camac, onde até hoje estão duas pedras que se assemelham a seres humanos.

E quando ela chegou ao lugar que é atualmente sua morada, ela virou pedra.

Sendo Cuni Raya uma divindade aquática, então o brilho dele nesta passagem, afirmam Salomon e Urioste, pode ser uma metáfora do brilho da água à luz do sol. Suponho que a água que brilha assim seja a dos rios e dos lagos, e não a do mar. A zangada Caiu Llana parece ter preferido, contudo, a vastidão do oceano, em direção ao qual se dirigiu correndo, levando com ela o filho do huaca trickster. O nome Pacha Camac se refere, na citação, a uma divindade costeira; já se vê que, em $O$ manuscrito de Huarochiri, as divindades acabam virando rochas, montes, montanhas. Cegada pelo ódio, ela não foi capaz de vislumbrar a nova aparência gloriosa do pai do seu filho. O huaca Cuni Raya Vira Cocha alcançou o litoral, entrou no mar (tal qual um rio, diria) e, segundo narra uma passagem que foi riscada no original da cosmogonia andina, continuou avançando até chegar à Espanha; diziam os antigos andinos, contudo, que ele havia partido, na verdade, para outra terra ou outro mundo.

Passarei agora a outro exemplo, tirado também de um clássico da literatura ameríndia, que relata esse ato transgressor e/ou miraculoso de engravidar uma virgem por intermédio da fruta de uma árvore frutífera. $\mathrm{Na}$ conhecida e controversa A lenda de Jurupari, recolhida no final do século XIX em nheengatu (a língua geral falada na época por diversas tribos) no norte do Brasil, e logo traduzida para o italiano por Ermanno Stradelli, que a publicou na Itália (o original, de autoria de um indígena mestiço brasileiro, Maximiano José Roberto, perdeu-se depois), lê-se, logo no início, a concepção milagrosa da divindade solar Jurupari, aqui na tradução para o português de Aurora Fornoni Bernardini:

Entre os recém-nascidos havia uma menina que devido à sua beleza esplendorosa foi chamada de Seuci. A Seuci da Terra era o retrato da Seuci céu e cresceu até a idade dos primeiros amores tão pura como a estrela da manhã. 
Um dia desejou comer da fruta do pihican e entrou na floresta. Encontrou facilmente as frutas desejadas e não teve dificuldade para recolhê-las: alguns macacos tinham derrubado algumas delas poucos minutos antes. A linda moça escolheu as mais maduras e bonitas e, juntando-as diante de si, começou a comê-las.

Elas eram tão saborosas que parte do suco, escorrendo entre os seios, descia e lhe banhava as partes mais recônditas, sem que ela tivesse conhecimento do fato.

Comeu até saciar-se, e só voltou para casa à hora das tristezas, contente por ter satisfeito um desejo que há muito nutria.

Sentia, porém, seus membros como que entorpecidos por uma estranha sensação, jamais antes experimentada.

Movida por um instinto material (sic), examinou-se atentamente e descobriu que sua virgindade já não mais existia, e que em suas vísceras havia algo de desconhecido.

Envergonhada, nada contou à sua mãe, e conservou cuidadosamente seu segredo, até que o tempo se encarregou de revelar seu estado.

Então, às perguntas das pessoas da tribo que que queriam vingar a afronta do violador, em sua simplicidade contou a história do pihican.

Dez luas depois ela pariu um menino robusto que superava, em beleza, a mãe e se parecia com o Sol. (Medeiros 275)

Esse trecho narra a concepção e o nascimento de Jurupari, nome que significaria, segundo se lê na lenda, "gerado pela fruta." Quando se compara a lenda amazônica, na versão de Roberto, com o manuscrito andino, muito anterior a ela, conforme se sabe, já que a primeira data do final do século XIX e o segundo do início do século XVII, nota-se imediatamente a coincidência na apresentação da concepção miraculosa de uma criança: em ambos os relatos, a mãe virgem não chega a ter contato direto com um ser humano, mas com frutas maduras, engravidando a partir do caldo destas. A lenda parece explicitar e esclarecer temas que ficaram mais ou menos implícitos na versão andina da 
relação interespécies, a qual é conhecida, ao que parece, de vários povos ameríndios e bastante explorada na literatura deles.

$\mathrm{Na}$ lenda, para começar, aparecem macacos em vez de uma ave, e cabe a esses animais derrubarem as frutas maduras no chão, as quais a mocinha recolherá em seguida. Mas esses macacos, ao que tudo indica, não colocaram o próprio sêmen nas frutas; eles são apenas um instrumento do verdadeiro pai de Jurupari, que é o Sol (o filho se parecia muito com o pai), uma divindade resplandecente, como o huaca andino. Seuci (nome dado à constelação das Plêiades) parece resignada com sua inesperada gravidez, e não se preocupa em saber quem é o pai da criança, ao contrário da divindade peruana, que não só desconfiava que um dos seres sobre-humanos que habitavam Huarochiri era o pai da criança, como acabou decidindo, após o nascimento dela, descobrir sua identidade, a fim de desmascará-lo publicamente. No caso da lenda, as pessoas da tribo reconheceram explicitamente que a virgem foi violada por alguém, e, em consequência, desejavam punir a afronta do violador, mas este não foi na ocasião identificado, pois a fruta (assim como os macacos que depois a derrubaram no chão) era apenas um instrumento que o Sol usou para alcançar seus fins escusos.

Quando se comparam os dois trechos citados, é fácil ver que o texto da lenda é mais desenvolvido que o do manuscrito, estando recheado de pormenores sugestivos, supostamente literários demais, para os críticos que contestam sua autenticidade indígena. Deve desconcertar esses críticos, por exemplo, o modo como o sumo da fruta banhou o corpo da virgem, desde os seios até vagina. Esse tipo de descrição minuciosa e pretensamente poética (e erótica) levou alguns comentadores, ao longo do século XX, a sugerir que o texto da lenda era uma contrafação do tradutor italiano, que teria adulterado a linguagem original ao acrescentar-lhe um sabor literário fin de siècle, às vezes róseo ou artificial demais, para agradar aos leitores da época; outros críticos, mais severos, opinaram que Stradelli teria até mesmo inventado a lenda em grande parte, o que é, a meu ver, um parecer delirante que não se sustenta, já que vários temas desenvolvidos nela, como esse da virgem violada que estou discutindo, aparecem em outras obras ameríndias. Ou seja, a lenda dialoga muito bem com outros relatos indígenas considerados autênticos. Há afinidades 
temáticas evidente entre eles, ainda que as estilísticas possam ser poucas e frágeis. $^{2}$

A mocinha se sente envergonhada quando descobre que está grávida, calando seu segredo, com medo da reação materna. Nada disso acontece no manuscrito, onde a mãe da criança quer a todo custo descobrir quem é o pai da criança. Quando o consegue, declara-lhe seu desprezo e se afasta dele, fugindo para o mar; prefere ser uma rocha (e esse é um destino recorrente na cosmogonia andina, que assim explica a configuração original do território montanhoso) a unir-se a um miserável andarilho, que, na verdade, é uma divindade esplendorosa. Portanto, as duas mulheres têm temperamentos opostos, e se ambas são violentadas da mesma forma, reagem depois de maneira muito diversa, decerto porque a primeira é uma divindade e a segunda, uma mulher comum. A andina é colérica, a amazonense, suave; aquela se mostra inconformada, esta, resignada.

A atitude passiva da mãe amazonense contribuiu, sem dúvida, para que a tribo aceitasse a violação como um fato consumado e reconhecesse, depois, a criança miraculosa como um novo chefe, ao qual se deveria entregar imediatamente as insígnias do cargo. Curiosamente (ou nem tanto), a lenda começa descrevendo uma situação em que, na Serra de Tenuiana, após uma epidemia, só restaram homens velhos, que as mulheres locais desprezavam como "carcaças" e pensavam jogar para os peixes, caso não pudessem revigorálos. Sabemos também que, no manuscrito, o pai da criança foi considerado um velho miserável, em razão de sua idade avançada e aparência lamentável. A tensão entre mulheres jovens e homens velhos é a mesma nos dois textos. $\mathrm{Na}$ lenda amazônica, a mulheres se banham num lago com o velho pajé e ficam a seguir todas grávidas, pois o pajé, na verdade, era um jovem disfarçado, e talvez se possa considerá-lo, até certo ponto, como um trickster, tal qual o huaca andino.

Neste segundo exemplo pode-se falar de violação coletiva das mulheres jovens, mas é preciso esclarecer também que elas desejavam ardentemente um parceiro jovem e viril, e de fato, quando se banharam à noite no lago, encontram-no, disfarçado de pajé decrépito, mas, na verdade, aquele parceiro era tudo o que elas desejavam do ponto de vista físico: forte e belo, um pai

\footnotetext{
${ }^{2}$ Sá resume e rebate as críticas mais contundentes à lenda.
} 
ideal para seus filhos. De fato, não fosse a ação dele, a aldeia, que parecia fadada a extinguir-se, não teria voltado a povoar-se tão rapidamente, nem Seuci, a futura mãe de Jurupari, cuja violação subsequente já comentei, teria nascido, junto com numerosas crianças de ambos os sexos. Aparentemente, a mulheres realizaram plenamente seus desejos, mesmo que não suspeitassem que seriam fecundadas de uma só vez pelo pajé: "As mulheres, cheias de contentamento, contavam umas às outras o alegre acontecimento, esquecendo que todas haviam assistido a ele e, tomadas às vezes por estranhas suspeitas que desapareciam diante dos fatos, examinavam-se cuidadosamente, para ter certeza de que aquilo não era um sonho" (Medeiros 274-75).

$\mathrm{Na}$ terceira cosmogonia que citarei agora, o papel da árvore (ou de seus frutos) nas relações sexuais ameríndias é explicitado e discutido pelo casal envolvido. Trata-se do poema maia-quiché conhecido sob o título Popol Vuh, cuja versão que citarei, do século XVII, é de autor desconhecido. Numa cena que se passa em Xibalba, o inframundo, temos uma relação conflituosa entre o povo "de cima" (que habita o mundo exterior) e o "de baixo" (que habita o mundo interior), a qual redundará na derrota dos dois heróis sobre-humanos, Hun Hun $\mathrm{Ah} \mathrm{Pu} \mathrm{(ou} \mathrm{Hun} \mathrm{Ah} \mathrm{Pu}$ ) e Vuqub Hun $\mathrm{Ah} \mathrm{Pu,} \mathrm{que} \mathrm{tentaram} \mathrm{lutar} \mathrm{com}$ os poderosos senhores de Xibalba. É nesse momento que surge a virgem X Kiq, que se aproximará, contrariando as ordens paternas, de uma árvore na qual a cabeça de um dos heróis derrotados tinha sido colocada. Eis o trecho em questão, numa tradução minha feita em colaboração com o professor inglês Gordon Brotherston:

Assim ela foi sozinha

E chegou lá

Sob a árvore,

Plantada no Pátio Empoeirado.

"Ah! O que é o fruto desta árvore?

Não é delicioso o que esta árvore dá?

Eles não devem se estragar;

Não devem ser desperdiçados.

E se eu pudesse cortar um só?"

Disse a mocinha então.

E então falou a caveira 
Que estava lá na árvore:

"Por que você deseja estas meras caveiras

Que se tornaram redondas nos galhos das árvores?"

Foi o que a caveira de Hun Ah Pu disse

Quando ele falou à mocinha.

"Você não as quer,"

Foi-lhe dito.

"Eu as quero muito,"

Disse a mocinha então.

"Está bem, você deve erguer sua mão direita.

Você vê agora?" disse a caveira.

"Sim,"

Disse a mocinha então.

E estendeu

A mão direita diante da caveira.

E assim a caveira lançou sobre ela sua saliva,

Que caiu então na palma da mão da mocinha.

$[\ldots]$

E assim a mocinha voltou de novo

Para sua casa.

Muitos avisos

Ela tinha recebido.

E imediatamente ela engravidou só do cuspo,

E assim foram gerados

Hun $\mathrm{Ah} \mathrm{Pu}$

E X Balam Ke.” (Brotherston and Medeiros 145-49)

Em alguns versos anteriores, o poema afirma que a cabeça de Hun Hun $\mathrm{Ah} \mathrm{Pu}$ (Um Caçador) havia ficado idêntica aos frutos da árvore, que era uma cabaceira. Ou seja, a sua caveira havia se transformado numa cabaça cheia de cuspo, ou sêmen. O herói sacrificado esclarece, diante da mocinha, após cuspir na sua mão, que a saliva de um homem é como sua natureza; por isso, seu filho é como seu cuspo. A partir desse encontro dos dois no Pátio Empoeirado, a descendência de Hun Hun $\mathrm{Ah} \mathrm{Pu}$, um guerreiro que parecia derrotado para sempre, fica garantida (o que é, cabe concluir, uma forma de vitória sobre 
Xibalba, que queria justamente exterminar sua linhagem). A Moça de Sangue, ou X Kic, algum tempo depois, subirá à superfície da Terra e dará à luz gêmeos, que crescerão no mundo externo e, quando adultos, descerão para Xibalba, para vingar a morte pai, o qual enterrarão com toda a deferência, instituindo o funeral maia.

Diferente das duas outras versões já comentadas, a árvore, nesta versão, por meio de um dos seus frutos, dialoga com a mocinha que ousou se aproximar dela. A caveira sabe que, mesmo sendo agora uma cabaça redonda, não deve ser muito atraente, e indaga se a mocinha realmente deseja colhê-la e cortá-la. Temos, novamente aqui, considerações sobre a aparência física e a beleza. Quando a mocinha confirma que quer muito o fruto, o herói morto (que ainda não está totalmente morto, pois não foi inumado), decide levar adiante a relação interespécies e cospe na sua mão direita. Entretanto, o diálogo entre os dois é ambíguo, pois o herói explica para a mocinha a função do cuspo apenas depois que ela havia recebido a saliva dele na palma estendida. De certa forma, podese dizer que ela foi ludibriada (violada), porque, antes, só havia assumido que desejava muito a cabaça, porém não declarou que consentiria em ficar grávida de Um Caçador. E não o declarou porque, aparentemente, não fora capaz de associar a cabaça com a cabeça de um homem atraente e viril. Para ela, a cabeça era apenas um fruto que ela estava vendo pela primeira vez na vida. Quando volta para casa, ela aparentemente aceita sua nova condição de moça grávida (cria-se assim um inesperado laço entre os dois mundos, o de baixo e o de cima), mas, para salvar-se, precisa fugir de Xibalba e buscar proteção na casa da sogra, no mundo exterior.

É interessante comparar sua situação com a das mulheres da lenda amazônica, que ficaram sem homens. Elas desejavam muito um companheiro (chegaram a pensar na possibilidade de mulher fecundar mulher), porque sabiam que, caso não engravidassem, a tribo seria extinta. Mas esse desejo, certamente, não significava que elas esperavam ficar todas grávidas de uma só vez, e de um único homem. Depois que tudo acontece, elas não protestam nem parecem se sentir ludibriadas, mas levam avante sua gravidez e dão à luz crianças de ambos os sexos. A reação da virgem peruana foi, ao contrário, de muita ira, como se sabe, pois não podia, de maneira alguma, aceitar o pai da criança. Talvez aceitasse a violação, mas não quem a violara. 
Então, comparando as três versões do mito da "virgem violada," caberia agora concluir que os heróis sobre-humanos que se servem de árvores para engravidar virgens desejam, por alguma razão, manter-se quase sempre ocultos; de fato, nem todos querem ou devem revelar, até o nascimento da criança, como ocorreu no caso do manuscrito, sua verdadeira identidade. Na lenda, a identidade do pai de Jurupari não é debatida explicitamente, pois ele, sendo o Sol, não está presente na Terra sob forma humana, não é alguém que a virgem viu, desprezou e rejeitou. Mas, ausentes ou presentes, esses personagens se tornam sempre atraentes e irresistíveis ao assumirem a condição de frutas sumarentas; é assim que os heróis obscuros ou desprezíveis se tornam de repente muito desejados e conseguem facilmente seduzir a virgem e engravidála. Porém, em todos os casos, é evidente que a virgem está sendo enganada por um sedutor; ela toma as coisas, ingenuamente, por aquilo que elas aparentam ser. Para ela, a fruta sumarenta é uma fruta madura, e um homem velho ou miserável, realmente um mendigo desprezível, quando, por trás dessas aparências ilusórias, existe, literalmente, outras "substâncias," que sua intuição não alcança.

Por outro lado, as mulheres virgens comentem graves transgressões nos mitos citados, sobretudo nos dois últimos casos. Por conta disso, são "punidas" sempre com a gravidez inesperada. As mulheres sem marido da lenda amazônica deveriam ter consultado o pajé sobre o que fazer na ausência de companheiros viris, mas não o fizeram, "violando o costume." Também elas são "violadoras," como o texto da lenda deixa explícito. Na cosmogonia maiaquiché, a virgem desobedeceu a um interdito paterno, que explicitamente a proibia de se aproximar da cabaceira.

A transgressão da huaca parece ter sido a soberba, ou o isolamento altivo, que a fez desdenhar da companhia masculina. Mulheres que desprezam os homens, por uma razão ou outra, acabam sendo seduzidas por árvores, frutos e raízes, na mitologia ameríndia. Claude Lévi-Strauss, talvez o maior estudioso dessa literatura, dedicou atenção ao tema, como falarei a seguir, citando apenas um de seus livros, Histoire de Lynx, publicado em 1991.

Num capítulo intitulado "Le fils de la racine," depois de afirmar que é muito difundido, nas "duas Américas" (a do Sul e a do Norte), o mito da mulher casada que se afasta da aldeia (ela é coletora de raízes, enquanto o marido é caçador) para encontrar-se, na floresta, com um animal sedutor, o 
grande mitólogo recorda que uma planta também pode suscitar numa mulher pensamentos eróticos, embora ela não espere necessariamente manter relações sexuais com raízes e galhos. A situação pode servir de ensejo, isto sim, para que ela invoque nesse momento "alguém"-um ser sobrenatural (que surgirá na forma de um pássaro, como se esclarece no capítulo citado) — a quem pede que venha satisfazê-la na sua solidão. Temos, neste exemplo, uma relação complexa, a qual envolve uma mulher, um vegetal e um ser sobre-humano; uma situação análoga, como se viu, envolvendo também esses três elementos, ocorreu na violação da huaca virgem, descrita no manuscrito peruano.

A relação com o vegetal também pode ocorrer literalmente. Os povos de língua salish, por exemplo, contam que uma moça que recusava todos os seus pretendentes teve de contentar-se com uma raiz quando quis se casar. Contam também que, enquanto recolhia raízes, uma mulher sentiu desejo de copular com elas. Outra mulher, perdida na mata e sentindo muita solidão, aceitou unirse a uma raiz sedutora. Neste último caso, ela engravida e da à luz um filho, que cresce ao lado dela, mas depois, quando descobre a verdade sobre a sua origem, ele a abandona, transformando-a antes em pedra, afogando-a num lago ou indo simplesmente embora, deixando-a para sempre sozinha na mata.

Nas minhas pesquisas sobre mitologia, venho trabalhado, há alguns anos, com a relação interespécies, sobretudo a de caçadores com animais sedutores, os quais, como a anta amazônica, podem unir-se a rapazes perdidos na floresta. Dessa relação, nasce uma criança que, depois, é levada para a aldeia de origem do caçador.

Neste ensaio, limitei-me a falar de mulheres virgens (seres sobre-humanos ou coletoras de frutos) e de suas relações ambíguas (e eróticas) com árvores frutíferas. $^{3}$ Quis enfatizar sobretudo a ação das divindades que,

\footnotetext{
${ }^{3}$ Os poderes mágicos dos vegetais podem também afetar diretamente os homens? Esse não é o assunto do meu ensaio, porém, gostaria de citar uma extraordinária experiência amazônica envolvendo um homem, narrada por Clarice Lispector em Água viva: "Tenho que interromper porque-Eu não disse? Eu não disse que um dia ia me acontecer uma coisa? Pois aconteceu agora mesmo. Um homem chamado João falou comigo pelo telefone. Ele se criou no profundo da Amazônia. E diz que lá corre a lenda de uma planta que fala. Chama-se tajá. E dizem que sendo mistificada de um modo ritualista pelos indígenas, ela eventualmente diz uma palavra. João me contou uma coisa que não tem explicação: uma vez entrou tarde da noite em casa e quando estava passando pelo corredor onde estava a planta ouviu a palavra 'João'. Então pensou que era sua mãe o tinha chamando e respondeu: já vou. Subiu mas encontrou a mãe e o pai ressonando profundamente" (60).
} 
momentaneamente, encarnam em árvores e frutos sumarentos, os quais se tornam pessoas, por meio da metonímia (a parte pelo todo). Essas pessoas são amorais, ou até mesmo imorais, se se quiser, mas na aparência física parecem apenas objetos naturais. Seria melhor aprender a jogar com elas, afirma Hyde, "ainda melhor desenvolver estilos (culturais, espirituais, artísticos) que permitam algum intercâmbio com o acidental e alguma aceitação das mudanças que a contingência sempre engendrará" (155).

\section{Obras Citadas}

Brotherston, Gordon, and Sérgio Medeiros, editors. Popol Vuh. Iluminuras, 2007.

Descola, Philippe. Diversité des natures, diversité des cultures. Bayard, 2010.

Hyde, Lewis. A astúcia cria o mundo: trickster: trapaça, mito e arte. Civilização Brasileira, 2017.

Lévi-Strauss, Claude. Histoire de Lynx. Plon, 1991.

Lispector, Clarice. Água viva. Rocco, 1998.

Medeiros, Sérgio, editor. Makunaíma e Jurupari: cosmogonias ameríndias. Perspectiva, 2002.

Sá, Lúcia. Literaturas da floresta: textos amazônicos e cultura latinoamericana. U Estadual do Rio de Janeiro, 2012.

Salomon, Fran, and George L. Urioste, editors. The Huarochirí Manuscript: A Testament of Ancient and Colonial Andean Religion. U of Texas P, 1991.

Taylor, Gerald, editor. Rites et traditions de Huarochiri. L'Harmattan, 2004.

Viveiros de Castro, Eduardo. Metafísicas canibais. Cosacnaify, 2015. 